INTERNACIONAL

\title{
Caso Duque con Colombia: Un caso de discriminación estructural
}

\author{
Case Duque v. Colombia: A case of structural discrimination \\ Camila Troncoso Zúñiga y Natalia Paz Morales Cerda \\ Universidad de Chile
}

\begin{abstract}
RESUMEN En este artículo se analizará críticamente la sentencia del caso Duque con Colombia dictada por la Corte Interamericana de Derechos Humanos el 26 de febrero de 2016, con el propósito de destacar la importancia de reconocer las situaciones de desigualdad estructural que afectan a determinados grupos de la población en la dictación de reparaciones adecuadas que permitan superar las condiciones de exclusión que causaron el conflicto.
\end{abstract}

PALABRAS CLAVE Orientación sexual, desigualdad estructural, reparaciones transformadoras, Corte Interamericana de Derechos Humanos.

\begin{abstract}
The aim of this article will be to critically analyse the judgement of the Inter-American Court of Human Rights of February 26, 2016 in the case Duque vs Colombia, to emphasize the importance of recognizing structural inequality situations that affect some social groups, with the purpose of stating adequate reparations that make possible to overcome the conditions of exclusion that caused the conflict.
\end{abstract}

KEYWORDS Sexual orientation, structural inequality, transformative reparations, Inter-American Court of Human Rights.

\section{Introducción}

El 26 de febrero de 2016, la Corte Interamericana de Derechos Humanos condenó al Estado de Colombia por vulnerar el derecho a la igualdad ante la ley y a la no discriminación de Ángel Duque, por no permitirle acceder en condiciones de igualdad a la pensión de sobrevivencia luego de la muerte de su pareja el año 2001, por tratarse de una pareja del mismo sexo. 
En aquel momento, la normativa interna colombiana disponía que únicamente quien fuere cónyuge, compañero o compañera permanente sobreviviente de sexo diferente al del causante tenía derecho a la pensión de sobrevivencia (Ley 100 de 1993), y que se denomina Unión Marital de Hecho a aquella formada entre un hombre y una mujer que, sin estar casados, hacen una comunidad de vida permanente. Igualmente, se denomina compañero permanente, al hombre y la mujer que conforman la Unión Marital de Hecho (Ley 54 de 1990).

El 2007 la Corte Constitucional de Colombia reconoció jurisprudencialmente a las parejas del mismo sexo los beneficios de pensión, seguro social y derechos de propiedad, al señalar que lo establecido en la Ley 54 de 1990 también aplica para las parejas del mismo sexo. Luego, en 2008, en la sentencia C-336, la misma Corte concluyó que las parejas permanentes del mismo sexo que acrediten dicha calidad tienen derecho a la pensión de sobrevivencia.

En el análisis del fondo, la Corte estimó que negar el acceso en condiciones de igualdad a la pensión de sobrevivencia constituyó un hecho ilícito internacional. Declaró a Colombia responsable por la violación al derecho a la igualdad y no discriminación contenido en el artículo 24 de la Convención Americana sobre Derechos Humanos (CADH), en relación con el artículo 1.1 del mismo instrumento. Con respecto a las reparaciones, la Corte estableció que su sentencia constituye una forma de reparación y ordenó al Estado: i) publicarla; ii) garantizar al señor Duque tramitar la solicitud a una pensión de sobrevivencia, y iii) pagar la cantidad fijada por concepto de daño inmaterial, además de costas y gastos.

A continuación, analizaremos las conclusiones a las que arribó la Corte, con particular énfasis en las consecuencias que la aproximación al caso generó en las reparaciones ordenadas. Utilizaremos el marco conceptual de la desigualdad estructural, con el propósito de sostener que la vulneración de los derechos del señor Duque es una manifestación de la discriminación histórica y sistemática a las parejas del mismo sexo. Finalmente, nos referiremos al rol de las reparaciones con vocación transformadora en la superación de la discriminación estructural.

\section{Derecho a la seguridad social de las parejas del mismo sexo}

La Corte se ha referido, indirectamente, al derecho a la seguridad social a través de vulneraciones a la propiedad (artículo 21 de la $\mathrm{CADH}$ ), a la progresividad en el desarrollo de los derechos sociales (artículo 26) y al derecho a la igualdad ante la ley (artículo 24).

En el caso Cinco Pensionistas (2003) el argumento relativo a la progresividad de los derechos sociales fue rechazado por considerar que no se afectaba la progresividad en general, pues los alegatos se referían a las circunstancias sufridas por un grupo 
de personas y no a una situación general ${ }^{1}$. La controversia en este punto difiere del caso Duque, pues en aquel lo que se buscaba dilucidar era si tenían o no derecho a un monto determinado de pensión; en el caso en comento, la controversia es si existe un derecho a dicha pensión.

En el caso Furlán y familiares $(2012)^{2}$ se había concedido una indemnización a la víctima de un accidente sufrido en un recinto militar. Dicho monto fue restringido debido a la dictación de la Ley 23.803 que, con el objetivo de disminuir la crisis económica, la modificó. Por lo tanto, la Corte buscó dilucidar si la restricción al derecho a la propiedad que la víctima tenía sobre dicha indemnización fue una restricción legítima o no. Nuevamente, no se cuestiona el derecho a la indemnización, sino el monto.

El Comité de Derechos Humanos ya había emitido un pronunciamiento en el caso Young con Australia (2003) sobre hechos similares al caso Duque. En éste analizó la diferencia entre parejas de hecho del mismo y de distinto sexo, tras lo cual señaló que una diferencia entre una pareja heterosexual casada y una heterosexual de hecho sí es objetiva y razonable, ya que las personas podrían escoger acogerse a los derechos que un determinado estado otorga ${ }^{3}$, pero ambas se ajustan a la definición de «miembro de una pareja», por lo que son aptas para recibir los beneficios de la pensión. Sin embargo, la distinción entre parejas de hecho heterosexuales y parejas del mismo sexo no es considerada objetiva y razonable, por lo que se vulneró el artículo 26 del Pacto Internacional de Derechos Civiles y Políticos. El Comité, según señala la Corte, indica que la distinción mencionada «no es razonable ni objetiva y no existen factores que justifiquen la existencia de la distinción, por lo que constituye una discriminación con base en la orientación sexual de las personas» ${ }^{4}$.

En Colombia, lo señalado anteriormente no tenía consagración legal. La Ley 100 de 1993, que instauró un sistema de seguridad social integral, señalaba que la pensión de sobrevivencia era otorgada en forma vitalicia al cónyuge o compañero permanente (artículo 10 $)^{5}$. El problema consistía, entonces, en determinar quiénes podían ser miembros de la pareja permanente. No fue hasta el 2007, gracias al pronunciamiento de la Corte Constitucional de Colombia, que las parejas permanentes del mismo sexo pudieron acceder a beneficios de seguridad social. Al respecto, el Tribunal recalcó el

1. Sentencia del caso Cinco Pensionistas con Perú, Corte Interamericana de Derechos Humanos, serie C 98, 28 de febrero de 2003, fondo, reparaciones y costas, párrafos 147 y 148.

2. Sentencia del caso Furlan y familiares con Argentina, Corte Interamericana de Derechos Humanos, serie C 246, 31 de agosto de 2012, excepciones preliminares, fondo, reparaciones y costas.

3. Caso Young con Australia, Comité de Derechos Humanos, 2003, párrafo 10.4.

4. Sentencia del caso Duque con Colombia, Corte Interamericana de Derechos Humanos, serie C 310, 26 de febrero de 2016, párrafo 111.

5. Caso Duque con Colombia, párrafo 72, haciendo alusión a Comité de Derechos Humanos. Caso Young con Australia, párrafo 10.4. 
principio de universalidad, que la dignidad pertenece a todos y, por tanto, no es posible que unas personas gocen de ciertos derechos y otras $\mathrm{no}^{6}$. Precisamente esa es la característica que la Ley 100 de 1993 y su reglamento omite, pues no consideran que a todos les correspondan los mismos derechos.

Así, aun cuando las parejas del mismo sexo no estén excluidas expresamente de los beneficios,

sí resultan de hecho exceptuadas del sistema de seguridad social, pues la falta de claridad del legislador ha conducido a implementar una situación contraria a los valores del Estado social de derecho, a los principios de reconocimiento y respeto por la dignidad de la persona humana, y a las normas que desde la Constitución amparan el libre desarrollo de la personalidad y su extensión: la libertad de opción sexual7.

Lo anterior deriva en una desprotección del sistema hacia miembros de la pareja del mismo sexo, la que debe ser enfrentada desde una mirada estructural del principio de igualdad, como explicaremos a continuación.

\section{Discriminación estructural a parejas del mismo sexo en Colombia}

Roberto Saba distingue dos nociones de igualdad (Saba, 2005: 18-19). La primera es una visión «individualista», que se corresponde con el principio de no discriminación y está anclada en las concepciones liberales clásicas que ubican al individuo esencialmente desprovisto de su contexto, con independencia de su pertenencia a un grupo social. Así, es necesario identificar en el tratamiento diferenciado ilegítimo una «intención» de discriminación que se caracteriza por la irracionalidad del criterio seleccionado, cuestión que desde el derecho internacional de los derechos humanos conocemos como «categorías sospechosas».

La segunda, en cambio, es una noción «estructural» de la igualdad, referida al principio de no sometimiento o exclusión. A la luz de esta concepción, Saba plantea que el propósito de la igualdad es evitar que existan grupos sometidos, excluidos o sojuzgados por otros grupos y, para ello, debemos reconocer al individuo en su contexto. De esta forma, una reinterpretación del principio de igualdad, ya no desde el prisma tradicional, propone la formulación de un concepto de igualdad que nos permita superar el statu quo o «perpetuación de inferioridad de grupos».

La igualdad estructural tiene la virtud de corregir desigualdades que no son posibles de asir desde las categorías sospechosas insertas en la interpretación tradicional,

6. Sentencia de la Corte Constitucional de Colombia, C-336/o8, 16 de abril de 2008, punto 6.8, demanda de inconstitucionalidad contra los artículos 1 (parcial) de la Ley 54 de 1990 y 47 (parcial), 74 (parcial) y 163 (parcial) de la Ley 100 de 1993.

7. Sentencia de la Corte Constitucional de Colombia, C-336/o8, punto 7. 
en la medida en que reconoce categorías sospechosas que se corresponden con la igualdad como no sometimiento y se dirige a «revertir prácticas sociales de exclusión y "perpetuación de situaciones de inferioridad»» (Saba, 2005: 28). Luego, responde a una subordinación sistemática que inhibe la eficacia de la igualdad de derechos y alude a la situación de determinados sectores de la población que, debido a prácticas sociales, culturales e institucionales, no gozan de derechos en las mismas condiciones que el resto de la sociedad.

Estos conceptos han sido recogidos por la jurisprudencia de la Corte. En el caso González y otras con México (2009), siguiendo la línea de lo expresado en el caso Penal Miguel Castro Castro con Perú (2006), afirmaba, en relación a la violencia de género, que los asesinatos, secuestros, desapariciones y las situaciones de violencia doméstica e intrafamiliar «no se trata de casos aislados, [...] sino de una situación estructural y de un fenómeno social y cultural enraizado en las costumbres y mentalidades» fundadas «en una cultura de violencia y discriminación basada en el género» ${ }^{8}$. En el caso Atala Riffo y niñas con Chile (2012), el mismo tribunal reconoció la existencia de una discriminación histórica y estructural que afectaba a las minorías sexuales, y que no puede perpetuarse ni reproducirse so pretexto de que no existe consenso al interior de algunos Estados sobre el pleno respeto por los derechos de estos grupos9. En el caso Trabajadores de la Hacienda Verde Brasil con Brasil (2016), la Corte reafirmó la obligación de los Estados de otorgar una protección especial a quienes se encuentren en una situación de vulnerabilidad; no basta que éstos se abstengan de violar los derechos, sino que es imperativa la adopción de medidas positivas. Luego, un Estado incurre en responsabilidad internacional en aquellos casos en que, habiendo discriminación estructural, no adopta medidas específicas ${ }^{10}$.

Resulta entonces esencial preguntarnos si las parejas del mismo sexo en Colombia se encuentran en una situación de desigualdad que podemos catalogar de estructural. Esto es, si el tratamiento diferenciado del cual han sido objeto las parejas del mismo sexo en el ámbito del derecho a la seguridad social responde a un conjunto de prácticas sociales, jurídicas e institucionales que han perpetuado su exclusión del goce del derecho en comento.

En exámenes de este tipo, la Corte ha atendido a elementos contextuales a partir de los cuales ha reconocido patrones colectivos de exclusión que afectan a determi-

8. Sentencia del caso González y otras («Campo Algodonero») con México, Corte Interamericana de Derechos Humanos, serie C 205, 16 de noviembre de 2009, excepción preliminar, fondo, reparaciones y costas, párrafo 229 .

9. Sentencia del caso Atala Riffo y niñas con Chile, Corte Interamericana de Derechos Humanos, serie C 239, 24 de febrero de 2012, fondo, reparaciones y costas, foja 92.

10. Sentencia del caso Trabajadores de la Hacienda Brasil Verde con Brasil. Corte Interamericana de Derechos Humanos, serie C 318, 20 de octubre de 2016, excepciones preliminares, fondo, reparaciones y costas, párrafo 337. 
nados grupos de personas; en los términos de Iris Marion Young (20011: 38-65), de opresión y dominación. Así, en el caso Campo Algodonero, la Corte hizo referencia a «un fenómeno social y cultural enraizado en las costumbres y mentalidades»" mientras que en el caso Trabajadores de la Hacienda Brasil Verde, afirmó que el tratamiento discriminatorio era histórico en razón de la posición económica de los trabajadores, destacando que no todas las violaciones de derechos humanos se presentan como hechos aislados, sino que en ocasiones éstas responden a contextos específicos e institucionales de negación de derechos humanos ${ }^{12}$.

Luego, en el caso de las parejas del mismo sexo en Colombia, si bien ni los representantes ni la Comisión aludieron a una noción de justicia que englobe las condiciones necesarias para el desarrollo y ejercicio individual de capacidades, así como a la cooperación y la comunicación colectiva (Young, 2004: 38), en cuyo seno podemos identificar situaciones de discriminación estructural, los representantes dieron indicios del contexto de discriminación al reconocer las dificultades de implementación de las sentencias de la Corte Constitucional en la materia.

En el ámbito patrimonial, las parejas del mismo sexo han estado históricamente desprotegidas, lo que ha lesionado su dignidad y el derecho al libre desarrollo de la personalidad ${ }^{13}$. Esto se ve reforzado por la legislación vigente en materia de pensiones de sobrevivencia y uniones maritales de hecho, que excluye expresamente a las parejas del mismo sexo. Sin embargo, la Corte no realizó un análisis de los estereotipos presentes al afirmar que el problema era normativo, sin hacer referencia a los problemas de implementación posteriores, en los cuales inciden aspectos sociales y culturales arraigados en la sociedad colombiana. En efecto, a pesar de la evolución jurisprudencial que ha permitido reconocer derechos a la comunidad LGTBI, los cambios han sido formales y parciales; la jurisprudencia favorable para las parejas del mismo sexo no ha tenido repercusión en un cambio normativo. Como señalare Bonilla, Colombia, «[e]n materia de orientación sexual [está] hasta ahora [aproximándose] al siglo XVIII. La discriminación social y la violencia en contra de la comunidad LGBT sigue siendo un hecho evidente» (Bonilla, 2010: 10). La violencia por prejuicio, el abuso policial, la ausencia de políticas públicas, la situación en los recintos penitenciarios, la forma diferenciada en que el conflicto armado ha afectado a la población LGTBI, entre otras, dan cuenta de que nos enfrentamos a un patrón social y cultural de conducta enraizado en la comunidad social y política ${ }^{14}$.

11. Sentencia del caso Caso Atala Riffo y niñas con Chile, párrafo 127.

12. Voto razonado del juez Eduardo Ferrer Mac-Gregor en el caso Trabajadores de la Hacienda Brasil Verde con Brasil, párrafo 56.

13. Sentencia de la Corte Constitucional de Colombia, C-075/07, 7 de febrero de 2007, demanda de inconstitucionalidad contra los artículos 1 y 2 (parciales) de la Ley 54 de 1990, modificada parcialmente por la Ley 979 de 2005 .

14. Al respecto, ver el informe alterno de la organización Colombia Diversa (2016). 
Cuando nos enfrentamos a casos como el del señor Duque, no podemos soslayar ese contexto, a la luz del cual la Corte debió ser capaz de reconocer una «disfunción sistemática inadmisible» ${ }^{15}$, que ha generado que a todo un grupo de la población se le niegue el goce del derecho a la seguridad social. Luego, la Corte debió responder las siguientes preguntas: a) ¿se refiere la política a un grupo que presenta características comunes?; b) ¿es el grupo vulnerable marginalizado o está en una posición de desventaja frente a otros; c) ¿es la causa de dicha situación el contexto histórico, económico o sociocultural?; d) ¿existen patrones sistemáticos de discriminación?, y e) la medida o norma en cuestión, ¿crea una situación de desventaja? (Pelletier, 2014: 215).

El caso en análisis presenta una situación que afecta a un grupo con características comunes: orientación sexual no heterosexual ${ }^{16}$. Las personas pertenecientes a dicho grupo se encuentran en una situación de desventaja en relación con quienes no pertenecen al mismo, toda vez que estas últimas sí pueden acceder a determinados beneficios sociales o patrimoniales, y es precisamente esa pertenencia la causa de la exclusión en el goce de derechos. Esta discriminación es histórica y se ancla en el entramado social y cultural, el cual responde a un patrón sistemático de discriminación que la norma consagra, con lo que perpetúa una situación de desventaja. Si bien la jurisprudencia de la Corte Constitucional intentó salvar aquello, aún persisten problemas de implementación que perturban el goce efectivo de los derechos, toda vez que la superación de la discriminación estructural exige adoptar medidas positivas que permitan eliminar las causas históricas de dicha desigualdad.

\section{Rol de la reparaciones y garantías de no repetición}

Los desafíos que enfrenta una sociedad que, como consecuencias de prácticas sociales, jurídicas e institucionales arraigadas en su cultura, ha perpetuado la exclusión de un grupo de la población del goce de determinados derechos son complejos. La reconstrucción de la confianza pública, que es la base de la convivencia social y política, requiere, por un lado, satisfacer las razonables expectativas de reparación de quienes han sido vulnerados en sus derechos; por otro lado, decisión de un Estado que restaure los imperativos éticos y jurídicos de igual consideración de todas las

15. Expresión utilizada por el Tribunal Europeo para referirse a un problema generalizado, resultado de un mal funcionamiento de la legislación, de la práctica administrativa que afectó el derecho de propiedad de un gran número de personas. No había sido motivada por un incidente aislado: el problema fue consecuencia de la conducta administrativa y normativa de las autoridades hacia una clase específica de ciudadanos. Sentencia del caso Broniowski con Polonia, Tribunal Europeo de Derechos Humanos, número 31443/96, 22 de junio de 2004, párrafo 189.

16. Las personas de un grupo determinado se reconocen por poseer características comunes (afinidades, modos de vida, etcétera)y se diferencian a su vez de otros, pero particularmente se definen por un sentido de identidad (Young, 2004: 40). 
personas. En ese contexto, cabe preguntarse desde qué perspectiva debemos pensar las reparaciones.

Uprimny y Saffon (2009: 33) plantean que el enfoque puramente restitutivo de las reparaciones resulta limitado, pues no atiende a los factores estructurales del conflicto, cuya transformación es esencial no sólo para garantizar la no repetición, sino para la superación de una situación estructuralmente injusta. Luego, el enfoque normativo tradicional de restitución integral, aunque deseable, tiene dificultades para superar violaciones masivas de derechos humanos en sociedad desiguales y excluyentes. En su lugar, proponen lo que han llamado «reparaciones transformadoras», que identifican como una oportunidad de impulsar transformaciones democráticas.

Los autores plantean que lo que resulta útil para comprender la esencia del enfoque de reparaciones con vocación transformadora es mirar la concepción original de la reparación en el derecho internacional. De acuerdo con Rhodri Williams, esta concepción surgió en las disputas internacionales, que por lo general versaban sobre bienes susceptibles de ser devueltos y, por tanto, la restitución constituía el componente esencial de la reparación y se consideraba jerárquicamente superior a cualquier otro componente. No obstante, cuando la reparación comenzó a utilizarse como mecanismo para enfrentar graves violaciones de derechos humanos, esta visión comenzó a resultar limitada, pues, como sostienen, «por lo general tales violaciones no atentan única ni principalmente contra bienes patrimoniales y en muchos casos los daños causados por las mismas impiden o tornan inadecuada la devolución de la víctima a la situación anterior» (Uprimny y Saffon, 2009: 39). En ese escenario, si se considera jurídica y socialmente deseable corregir el desequilibrio producido en aras de satisfacer los principios democráticos, no parece suficiente pensar en la restitución como el elemento central de la reparación.

La jurisprudencia constante de la Corte (Nash, 2009: 95-104) ha conjugado la restitución, la compensación, la rehabilitación, la satisfacción y las garantías de no repetición como componentes de la reparación, dependiendo de cada caso. De esta forma, mediante la restitución se busca devolver a la víctima a la situación que se encontraba antes de producirse la violación de sus derechos, cuando ello sea pertinente. A través de la compensación se busca reparar a la víctima por los daños sufridos, lo que incluye costos, gastos, pérdidas de ingreso y oportunidades. Los mecanismos de rehabilitación, por su parte, incluyen medidas de atención que pueda requerir la víctima, como, por ejemplo, atención médica, jurídica o social. Las medidas de satisfacción buscan reconocer públicamente el daño sufrido por la víctima y, a través de ello, dignificarlas. Las garantías de no repetición consisten en reformas institucionales $\mathrm{u}$ otras medidas que buscan evitar que las violaciones de derechos que se trate no vuelvan a ocurrir.

La vocación transformadora debiese hilvanar los cinco elementos y favorecer reparaciones cuyo propósito es subvertir las relaciones de poder que trasuntan las 
estructuras que permitieron la vulneración de los derechos fundamentales de un determinado grupo social. No viene a reemplazar los mecanismos descritos, sino a nutrirlos, propiciando un cambio en las dinámicas que dieron lugar a las violaciones de derechos humanos que se busca reparar.

En esta línea, en el caso Campo Algodonero la Corte recordó que si se tiene en cuenta la situación de discriminación estructural, las reparaciones debían tener una vocación transformadora, de tal forma que tengan un efecto correctivo y no sólo restitutivo, pues no era admisible una restitución a la misma situación estructural de violencia y discriminación ${ }^{17}$. Lo mismo en el caso Atala Riffo y niñas, ocasión en la cual el tribunal sostuvo que, a la luz de los actos discriminatorios que se relacionan con la reproducción de estereotipos, asociados a la discriminación estructural e histórica que han sufrido las minorías sexuales,

algunas de las reparaciones deben tener una vocación transformadora [...], de tal forma que las mismas tengan un efecto no sólo sustitutivo sino también correctivo hacia cambios estructurales que desarticulen aquellos estereotipos y prácticas que perpetúan la discriminación contra la población $\mathrm{LGTBI}^{18}$.

En definitiva, las reparaciones deben atender a la naturaleza de la violación de derechos humanos que se trate y al contexto en el cual incidirán, con el propósito de generar un cambio estructural. En este caso, el sometimiento y la exclusión histórica de las parejas del mismo sexo desnuda las deficiencias de la reparación restitutiva y justifica una reparación con vocación transformadora.

\section{Reflexiones finales}

El caso en comento concitó expectación porque, con posterioridad a la sentencia del caso Atala Riffo y niñas, este tribunal no había vuelto a pronunciarse sobre discriminación por orientación sexual. Además, se afectó el goce del derecho a la seguridad social, temática sobre la cual la Corte se ha pronunciado escasamente y en forma indirecta. Por ello, representaba una oportunidad para fortalecer su jurisprudencia en materia de igualdad y no discriminación, particularmente aquella que afecta a las parejas del mismo sexo. Sin embargo, nos encontramos con un silencio que contrasta con los importantísimos avances que la Corte ha realizado tanto en materia de igualdad y no discriminación, como en materia de reparaciones.

El tímido análisis que realizó la Corte para sostener que Colombia vulneró el derecho a la igualdad y no discriminación prescindió de elementos contextuales que permitieran reconocer fenómenos de discriminación históricas, con lo que ignoró la

17. Caso González y otras ("Campo Algodonero») con México, párrafo 450.

18. Caso Atala Riffo y niñas con Chile, párrafo 100. 
sistemática exclusión a la que han sido sometidas las parejas del mismo sexo. Esta deficiencia tiene importantes consecuencias prácticas, toda vez que la identificación de una situación de desigualdad estructural obliga a los Estados no sólo a evitar acciones discriminatorias, sino a adoptar medidas positivas para eliminar las causas históricas de dicha desigualdad.

Desconocer la existencia de patrones sociales de exclusión fuertemente arraigados en la sociedad colombiana, los que deben ser cuestionados y subvertidos en aras de la igual consideración de todas las personas, determinó que la Corte fuera discreta en las reparaciones. Esto, pues una reparación puramente restitutoria, como la otorgada, no asegura uno de los objetivos centrales de la reparación, que es garantizar la no repetición de la vulneración de derechos que se trate, toda vez que deja intactas las condiciones de exclusión que se encuentran en la base del conflicto.

En suma, la sentencia del caso Duque con Colombia ha dejado una importante deuda en el reconocimiento de situaciones de desigualdad estructural que afectan a la población LGTBI, pues ha revelado una Corte que, lejos del activismo que la caracterizó en el caso Atala Riffo y niñas, ha actuado de forma insuficiente.

\section{Referencias}

Bonilla, Daniel (2010). «Parejas del mismo sexo en Colombia. Tres modelos para su reconocimiento jurídico y político». Anuario de Derechos Humanos, 6: 183-20o. DOI: 10.5354/0718-2279.2010.11492.

Colombia Diversa (2016). «Situación de derechos humanos de las personas LGBT en Colombia, 2010-2015». Disponible en http://bit.ly/2uRoGle.

Nash, Claudio (2009). Las reparaciones ante la Corte Interamericana de Derechos Humanos (1988-2007). Santiago: Centro de Derechos Humanos, Facultad de Derecho Universidad de Chile.

Pelletier, Paola (2014). «La 'discriminación estructural' en la evolución de la Corte Interamericana de Derechos Humanos». Revista IIDH, 60: 205-215. Disponible en http://bit.ly/2eIIrpa.

SABA, Roberto (2005). «(Des)igualdad estructural». Revista de Derecho y Humanidades, 11: 123-147. Disponible en http://bit.ly/2tUcL2o.

UPRIMNY, Rodrigo y Paula SAFFON (2009). «Reparaciones transformadoras, justicia distributiva y profundización democrática». En Catalina Díaz Gómez y otros (editores), Reparar en Colombia: Los dilemas en contextos de conflicto, pobreza y exclusión (pp. 31-60). Bogotá: ICTJ; DeJuSticia.

YounG, Iris Marion (2004). «Five faces of oppression». En Lisa Heldke y otros (editores), Oppression, privilege and resistance. Boston: McGraw Hill.

-. (2011). Justice and the politics of difference. Nueva Jersey: Princeton University Press. 


\section{Sobre las autoras}

Camila Troncoso Zúñ Iga es abogada. Licenciada en Ciencias Jurídicas y Sociales de la Universidad de Chile. Coordinadora de gestión académica de la Escuela de Postgrado, Facultad de Derecho de la Universidad de Chile. Investigadora de la Fundación Diálogo Jurisprudencial Iberoamericano. Su correo electrónico es camila. troncoso@derecho.uchile.cl.

Natalia Paz Morales Cerda es abogada. Licenciada en Ciencias Jurídicas y Sociales de la Universidad de Chile. Abogada del Departamento de Reformas Legales del Ministerio de la Mujer y la Equidad de Género. Su correo electrónico es natapazmorales@gmail.com. 
